\title{
Endocrine Regulation of the Form and Function of Axonal Arbors During Insect Metamorphosis
}

\author{
R. B. Levine, ${ }^{\star}$ J. W. Truman, $†$ D. Linn, ${ }^{\star}$ and C. M. Bate $\ddagger$ \\ *Department of Biology, Rice University, Houston, Texas 77005, †Department of Zoology, NJ-15, University of \\ Washington, Seattle, Washington 98195, and $\neq$ Department of Zoology, University of Cambridge, Cambridge CB2 \\ 3EJ, England
}

\begin{abstract}
By discrete manipulation of the endocrine cues that control insect metamorphosis, it has been possible to examine the mechanisms governing the growth of neural processes during development. During the transition from larva to pupa in the hawkmoth, Manduca sexta, identified sensory neurons reorganize their central projections to evoke a new behavior - the gintrap reflex. Topical application of a juvenile hormone analog to the peripheral cell bodies of these sensory neurons during a critical period of development caused them to retain their larval commitment rather than undergo pupal development with the rest of the animal. The sensory neurons retained the larval arborization pattern within the pupal CNS and were unable to evoke the gin-trap reflex. Thus, the hormonal environment of the cell body is critical for controlling growth and synapse formation by distant axonal processes.
\end{abstract}

Neuronal differentiation can be influenced markedly by endocrine cues present during critical periods of development (Arnold and Gorski, 1984). In the vertebrates, steroid hormones have been implicated in the regulation of dendritic growth (DeVoogd and Nottebohm, 1981; Gurney, 1981), cell number (Breedlove and Arnold, 1983), and synaptic connectivity (DeVoogd et al., 1985; Raisman and Field, 1973). In most cases, however, it is difficult to determine whether individual neurons are influenced by the hormone directly or indirectly through effects on other neuronal or non-neuronal cells. Potentially analogous steroid effects are evident during the metamorphic reorganization of insect nervous systems. During insect metamorphosis many neurons that are functional during larval life undergo a period of redifferentiation, growing new processes and forming new synaptic connections in preparation for adult life (Levine, 1984; Levine and Truman, 1982, 1985). Since the insect developmental hormones 20-hydroxyecdysone (20-HE) and juvenile hormone $(\mathrm{JH})$ are known to be crucial factors in controlling the metamorphosis of other tissues (Riddiford, 1980), it seems likely that these hormones are also involved in regulating changes within the CNS, and recent evidence lends support to this idea (Truman and Schwartz, 1984; Weeks and Truman, 1985). The precise timing and punctuated nature of the events that comprise insect metamorphosis make it a particularly favorable system for analyzing the induction and regulation of developmental changes, as well as the potential involvement of endocrine signals. The present results demonstrate that the

\footnotetext{
Received May 24, 1985; revised Aug. 21, 1985; accepted Aug. 22, 1985.

Supported by NSF Grant BNS-8308907 to R.B.L. We thank Dr. S. R. Reiss for valuable technical help during the initial phases of this study, R. K. Murphey and D. Possidente for their advice on sectioning, and Barbara Fairbanks for preparing the manuscript. We also wish to acknowledge Drs. G. Staal and S. J. Kramer of Zoecon Corp. for their generous gift of methoprene.

Correspondence should be addressed to R. B. Levine at Department of Biology, Rice University, P.O. Box 1892, Houston, TX 77251
}

Copyright (C) 1986 Society for Neuroscience $0270-6474 / 86 / 010293-07 \$ 02.00 / 0$ endocrine environment of individual sensory neurons can control the shape of their axonal arborizations and the synaptic connections they make.

In the hawkmoth, Manduca sexta, metamorphosis becomes possible following a decline in the hemolymph titer of $\mathrm{JH}$ and begins when the larva is subsequently exposed to $20-\mathrm{HE}$ in the absence of JH (Riddiford, 1980; see Fig. 1). This latter endocrine event causes the polymorphic epidermal cells, along with other tissues, to become committed to pupal differentiation and temporarily insensitive to JH. Following the small "commitment" pcak of ccdystcroids, there is a sccond "prepupal" increase in the hemolymph titer of the steroid, during which cells express their committed state and the new pupa is formed. JH reappears during the prepupal peak to prevent precocious development of adult structures (Kiguchi and Riddiford, 1978).

The pupal structures that differentiate during the final four days of larval life, include three pairs of sensory structures located bilaterally along the anterior-lateral margins of abdominal segments 5, 6, and 7. These "gin-traps" each consist of a cuticular pit containing about 20 mechanoreceptive hairs, which, when stimulated, evoke a reflexive contraction of the ipsilateral longitudinal muscles in the next anterior segment (Bate, 1973a). The sensory neurons innervating each hair are retained from the larval stage, where they innervated mechanoreceptive hairs that covered the body surface (Bate, 1972; Levine et al., 1985). The cell bodies of the sensory neurons lie in the periphery, beneath the sensory hair, and during the larval-pupal transition their centrally projecting axons are retained. Although the motoneurons excited by these sensilla are the same in both stages (Levine and Truman, 1985), the nature of the response is very different in the larva and the pupa. In the larval stage, stimulation of small groups of receptors in the presumptive gin-trap region causes weak excitation of ipsilateral body wall motoneurons in several segments. In addition, the larval response is gated by proprioceptive input. In pupae, however, stimulation of single sensory neurons evokes a much stronger, all-or-none response that is confined to the ipsilateral motoneurons innervating the anterior segment (Bate, 1972, 1973b; Levine and Truman, 1983; Levine et al., 1985). The pupal response is not subject to proprioceptive influence and is terminated by strong inhibition of the motoneurons. This behavioral change presumably reflects alterations at several levels in the polysynaptic reflex circuit (Bate, 1973c), but one clear change is that the sensory neurons show a marked increase in the extent of branching within the CNS during the larval-pupal transition (Levine et al., 1985). The following experiments were designed to determine whether these changes were controlled by hormonal cues available to the peripheral sensory cell body, or whether changes in JH and ecdysteroid titers influenced sensory cell development by altering cues available to their axon terminals in the CNS. 

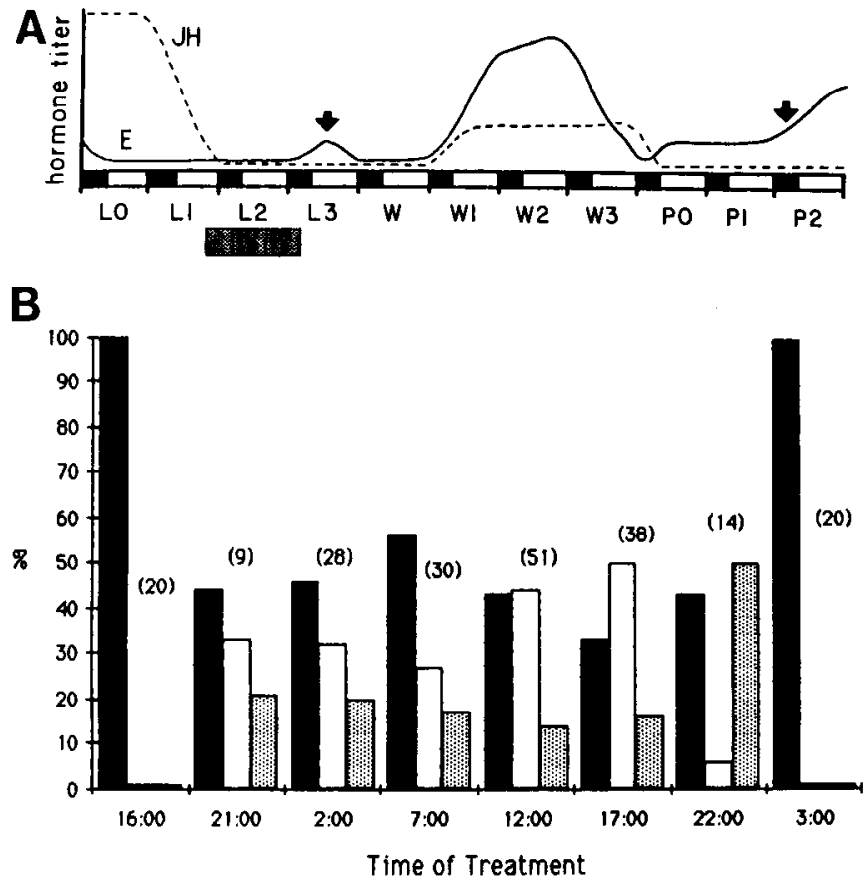

Figure 1. Hormone titers and the period of sensitivity to $\mathrm{JH}$ analog treatment. $A$, Relative titers of juvenile hormone $(J H)$ and ecdysteroid $(E)$ during the last larval instar and early pupal stage (adapted from Bollenbacher et al., 1981, and Riddiford, 1980). LO-W3, days of the last larval instar. After larval day $3(L 3)$, the caterpillar stops feeding and begins to wander $(W)$ in search of a suitable pupation site. $P O-P 2$, first 3 days of the pupal stage. The black-and-white bars on the time axis refer to the light/dark cycle (lights on, 0700; lights off, 2400). Arrows point to the small "commitment" peak of ecdysteroids and the later pupal peak that normally triggers adult development. The middle, "prepupal" peak of ecdysteroids causes cells to express their committed state (see text). The stippled bar at the bottom marks the period shown in $B$. $B$, Effects of $\mathrm{JH}$ analog treatments at different times during the final larval instar. The JII analog was applied at the times shown on the abscissa and was left in place for approximately $17 \mathrm{hr}$. The animals were then assayed behaviorally and visually on the day of pupation. Animals treated before 2100 on L1 or after 2200 on L2 formed normal gin-traps which could evoke the pupal reflex (normal, $\square$ ). Treatments between these times were sometimes without effect but could also result in either larval patches with sensilla that could not evoke the gin-trap reflex (larval patch, $\square$ ) or gin-traps with sensilla of normal appearance that were nevertheless unable to evoke the reflex (pupal patch, $⿴$ ). The numbers in parentheses refer to the number of animals treated at each time.

\section{Materials and Methods}

\section{Experimental animals}

Tobacco hornworms, Manduca sexta (L.), were reared individually on an artificial dict (Bcll and Joachim, 1978) under long-day conditions (17L:7D), at $26^{\circ} \mathrm{C}$. The animals pass through five larval instars before entering the pupal stage. Animals to be treated at specific times were chosen on the basis of external markings a few hours prior to the molt into the fifth instar. In this way their age could be determined accurately. Following treatment (see below) the animals were allowed to complete pupal development.

\section{Hormone treatment}

Larvae to be treated were immobilized by brief $\mathrm{CO}_{2}$ exposure. The $\mathrm{JH}$ analog, methoprene (ZR 515, Zoecon Corporation), was mixed at a concentration of $1 \mu \mathrm{g} / \mathrm{ml}$ in melted soft dental wax (Columbus Dental), and a film of the melted mixture $\left(50^{\circ} \mathrm{C}\right)$ was applied to the presumptive gin-trap region over an area ranging from 1 to $8 \mathrm{~mm}^{2}$. The wax solidified immediately and was left in place for 15-17 hr. At the end of this period the wax was removed with a piece of tissue paper, and the animal was allowed to complete pupal development.

\section{Histology}

Individual sensory neurons were stained either on the day of pupation or $4 \mathrm{~d}$ later to assess recovery. Staining was accomplished using the technique described in detail by Levine et al. (1985). Briefly, an individual hair was surrounded by a well of petroleum jelly and the tip was clipped-off under distilled water with a pair of fine forceps. The water was replaced with $100 \mathrm{mM} \mathrm{CoCl}_{2}$ to which $1 \%$ dimethylsulfoxide had been added. Animals were then placed in a humid chamber at $4^{\circ} \mathrm{C}$ for 4-5 d. At this point, the nervous system was removed from the animal and processed using a modified silver-intensification procedure (Bacon and Altman, 1977). Stained neurons were drawn in whole mount at $500 \times$ with a camera lucida attachment to a Zeiss compound microscope. The terminal processes of the stained sensory neurons were then measured by tracing the drawings on a digitizing tablet connected to a microcomputer. Ganglia were sectioned at $10 \mu \mathrm{m}$ after being reimbedded in an Epon/Araldite mixture (Johnson and Murphey, 1985; Mollenhaur, 1964).

\section{Electrophysiology}

Intracellular recordings from the body-wall motoneurons of pupae were obtained using techniques described elsewhere (Levine and Truman, 1982,1985 ). Bricfly, 1- or 2-d-old pupac werc pinned to a wax block, and a strip of dorsal cuticle was removed. Following removal of the gut, the body cavity was rinsed with modified Weever's saline (Levine and Truman, 1985; Weevers, 1966). After supporting individual segmental ganglia on a metal platform, motoneurons were impaled with glass microelectrodes filled with $2 \mathrm{~m}$ potassium acetate, with tip resistances between 25-40 M . The motoneurons that participate in the gin-trap reflex innervate lateral body-wall muscles in the segment anterior to the gin-trap. The motoneuron somata lie one segment anterior to their target muscle and are clearly visible along the dorsal midline of the segmental ganglion. Each motoneuron's identity was confirmed on impalement by depolarizing it to threshold and monitoring muscle contraction.

Extracellular recordings of sensory neuron axons were obtained using electrolytically sharpened tungsten "hook" electrodes that were placed under the nerve inncrvating the gin-trap (Batc, 1973a). The same clectrode could be used for stimulating afferent axons. Sensory neurons were activated mechanically by moving the associated hairs with a fine brush.

\section{Results}

\section{External appearance and behavioral effectiveness of treated areas}

The study of the role of hormonal cues in the metamorphosis of these sensory neurons was made possible by the fact that when $\mathrm{JH}$ is applied topically in low dosages, it will affect only the cells underlying the site of application (see Wigglesworth, 1954). Small areas in the presumptive gin-trap region of the larval epidermis were treated topically with a $\mathrm{JH}$ analog mixed in a wax base (see Materials and Methods) at various times during days L1-L3 of the last larval stage. The sensory cell bodies, lying in the epidermis at the base of each hair, were thereby exposed to a different hormonal environment than were their terminal processes within the CNS. As detailed in Figure 1 , last instar larvae normally experience a decline in the $\mathrm{JH}$ titer followed by a small rise in the level of ecdysteroids in the blood on day L3. This first ecdysteroid peak in the absence of $\mathrm{JH}$ is crucial for pupal commitment of the polymorphic epidermal cells (Riddiford, 1980, 1985) and, therefore, seemed likely to be important for the induction of pupal development of the sensory neurons. Different tissues and areas of the body surface are known to have slightly different periods of sensitivity (Truman et al., 1974), so the JH analog was applied at various times between the normal decline in blood levels of $\mathrm{JH}$ and the small ecdysteroid peak and left in place for $17 \mathrm{hr}$.

The gin-trap sensilla are formed, like other epidermal sensory structures in insects, by a hair-secreting tricogen cell and a socket-forming tormogen cell (Bate, 1978). In the larval stage, a thin hair and a tight-fitting socket are produced by these cells, while the epidermal cells produce a soft green cuticle. Later, in prep- 


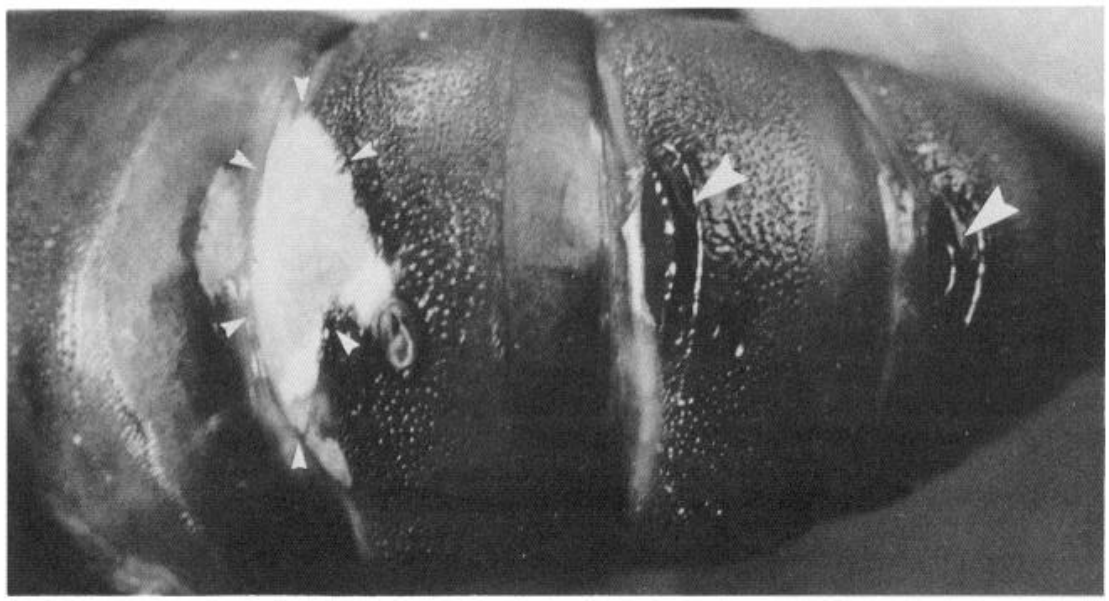

Figure 2. Larval patch resulting from application of the $\mathrm{JH}$ analog. The photograph shows the lateral aspects of abdominal segments 4-7 of a Manduca pupa. Anterior is to the left; dorsal is up. The large arrows point to normal gin-traps on segments 6 and 7 , while a large larval patch on segment 5 is encircled with small arrows. The larval patch has the blue-green color typical of larval epidermis and is covered with larval-like hairs, whereas the rest of the animal is the normal brown pupal color.

aration for the pupal stage, the same cells secrete shorter, darker hairs, which sit on a small mound (Levine et al., 1985). These gin-trap sensilla sit within a small depression in the rigid brown pupal cuticle secreted by the epidermal cells. Thus, the tricogen and tormogen cells are polymorphic and are similar in this respect to the epidermal cells, which secrete different cuticular proteins at larval and pupal molts (Riddiford, 1985). The gintrap region in areas treated with the $\mathrm{JH}$ analog could therefore be classified as either larval or pupal patches based on the appearance of the cuticle and sensilla in the region.

As seen in Figure 1, 25-50\% of the larvae treated just prior to the commitment peak became otherwise normal pupae, with a small larval patch at the site of hormone application (Fig. 2). In treated areas, therefore, the epidermal, tricogen, and tormogen cells again secreted larval structures at the pupal molt, so that the epidermis and sensilla within the patches retained their larval appearance. The size of the larval patch varied, depending on the size of the treated area. Thus, with small applications of the $\mathrm{JH}$ analog it was possible to generate small larval patches that replaced only part of a gin-trap. In the pupal portion of such mosaics, sensilla were situated within a small pit, were short, and sat on a small mound, while the larval portions were green and bore sensilla of larval appearance.

All treated animals were tested on the day of pupation for their ability to display the gin-trap behavior in response to tactile stimulation of hairs in the treated area. The typical pupal response consists of a rapid, all-or-none contraction, which is restricted to the ipsilateral body-wall muscles of the next anterior segment. Sensilla within a larval patch never evoked this response. Instead, as is the case in normal fifth instar larvae, single sensilla evoked no behavioral response, while brushing a small group of hairs led to a slow flexion or rotation of the abdomen. Importantly, the other gin-traps on the animal functioned normally, indicating that the effect was specific to those sensory neurons underlying the site of $\mathrm{JH}$ analog application. To control for the possibility that wax application simply damaged the underlying sensilla, wax not containing the $\mathrm{JH}$ analog was applied during the sensitive period. Normal gin-traps formed in these areas, and stimulation of the associated hairs evoked the typical pupal gin-trap response. Further controls for sensory cell damage are detailed below.

Several of the animals treated bore gin-traps in the treated region that had a normal pupal appearance but could not evoke the pupal reflex. Although such cases were not restricted to a particular treatment time, they were most prevalent when treatment began during the last $5 \mathrm{hr}$ of the sensitive period (Fig. 1). The treated gin-traps and associated sensory hairs in these animals were indistinguishable from those on normal pupae, but they evoked no response if stimulated individually or a slow contraction of muscles in several segments when stimulated as a group. In most instances where larval patches replaced only part of a gin-trap, the sensory hairs within both larval and pupallooking regions were incapable of evoking the gin-trap behavior; in some cases, however, sensilla within the pupal region were able to evoke the reflex.

During the period of sensitivity, approximately $40-55 \%$ of the animals treated showed no effect. To a large extent this percentage depended on the concentration of $\mathrm{JH}$ analog applied. A larger percentage of animals (approximately 90\%) were unaffected when the $\mathrm{JH}$ analog concentration was reduced 10 -fold $(0.1$ rather than $1.0 \mu \mathrm{g} / \mathrm{ml})$. At higher dosages $(2.0 \mu \mathrm{g} / \mathrm{ml})$, more larval patches occurred, but nonspecific effects were observed as well. Specifically, the gin-trap contralateral to the treated one or those on other segments failed to function normally, suggesting that systemic effects had occurred.

One interpretation of these results is that the treated sensory neurons retained their larval commitment and failed to form CNS connections appropriate for participation in the gin-trap reflex. Moreover, the dissociation of sensory cell effects from those on surrounding cell types suggests that the hormone sensitivity of the neurons is greater or that their hormone-sensitive period is later or more prolonged than that of the cells producing the associated hair, socket, and surrounding cuticle. The following experiments were designed to test these ideas.

\section{Function of treated sensilla}

The inability of treated sensilla to evoke the pupal reflex was not due simply to a failure in stimulus transduction. Treated sensory neurons within nonfunctional pupal areas and most larval patches responded like their untreated pupal counterparts to mechanical displacement of the associated hair (Fig. 3; compare with Bate, 1973a), but failed to evoke a motor response. This is reminiscent of the larval situation where single sensilla are seldom capable of evoking a motoneuron response (Levine et al., 1985). Stimulation of single hairs on the untreated control side, however, evoked normal gin-trap responses consisting of a rapid depolarization and a high-frequency burst of action potentials (Fig. 3). In some instances we were unable to record afferent responses from sensory neurons within experimentally produced larval patches, indicating a possible abnormality in the stimulus transduction process. In all cases, however, electrical stimulation of the afferent axons of treated sensory neurons failed to evoke the typical pupal motor response.

\section{Central arborizations of treated sensilla}

Normally, during the last $4 \mathrm{~d}$ of larval life, sensory neurons lying within the presumptive gin-trap region expand their terminal arborizations within the CNS (Levine et al., 1985). In order 


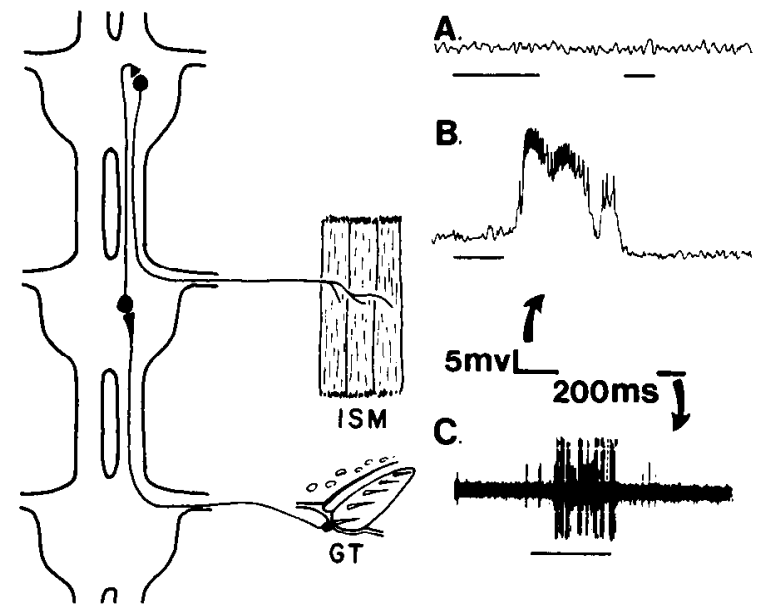

Figure 3. Responses to tactile stimulation of sensory neurons. $A$ and $B$, Intracellular recordings from intersegmental muscle motoneurons. $A$, Tactile stimulation of a treated sensillum (solid lines below record) evokes no response in a motoneuron innervating the ipsilateral side of the next anterior segment. $B$, Stimulation of a normal gin-trap hair from the control side of the same animal results in a high-frequency burst of action potentials in an ipsilateral motoneuron, which is terminated by inhibition. $C$, Tactile stimulation of a treated sensory hair that is unable to evoke a gin-trap response results in a normal sensory neuron response (recorded extracellularly from the afferent nerve). Insert, Circuit responsible for the gin-trap reflex. An unidentified interneuron is interposed between sensory and motoneurons.

to determine whether this sensory neuron growth is related to their ability to evoke the gin-trap reflex and to assess the effects of hormone manipulation, individual sensory neurons were stained after the animals entered the pupal stage. The processes of these sensory neurons enter the CNS in their segmental ganglion, where they branch minimally before proceeding to the next anterior ganglion to terminate. Since these anterior processes undergo the most dramatic change during pupal development, we have concentrated our analysis on this region of the neurons. The central projections of treated sensory neurons from larval patches and nonfunctional pupal gin-traps retained a larval morphology. In both affected groups the sensory neurons showed less total length of terminal arborization, with fewer branch points than did their normal counterparts at the time of pupal ecdysis (Table 1, Figs. 4 and 5). The extent of branching was, in fact, similar to that of normal larval sensory neurons. These effects on terminal branching were apparently not due to the JH analog acting on CNS sites, because contralateral gintraps that projected to the same ganglion were functional, and their sensory neurons developed the normal pupal morphology in the CNS (Figs. 4 and 5, Table 1). Further evidence for the peripheral nature of the effects comes from cases where small applications of the $\mathrm{JH}$ analog caused the formation of mosaic gin-traps containing patches of larval and pupal cuticle. Sensory neurons within the pupal area that could evoke the gin-trap reflex showed a normal pupal branching pattern within the same area of ncuropil in which their abnormal peripheral neighbors had larval-like arbors.

\section{Recovery of response}

Following entry into the pupal stage there is an ecdysteroid surge that normally triggers adult development (Bollenbacher et al., 1981; Riddiford, 1985; see Fig. 1). For the treated sensory neurons, however, this is the first time that they have experienced a high level of $20-\mathrm{HE}$ in the absence of $\mathrm{JH}$, the signal that normally triggers pupal differentiation. Accordingly, sensilla that could not evoke the pupal reflex on the day of pupation acquired the ability to evoke the gin-trap reflex within $4 \mathrm{~d}$. Furthermore, treated sensory neurons stained $4 \mathrm{~d}$ after pupation had expanded their terminal arbors and acquired the pupal branching pattern within the CNS (Table 1, Fig. 4). In response to these hormonal cues the epidermal cells within experimentally induced larval patches began to secrete a new pupal cuticle. As a result, tactile stimulation of hairs within these patches was usually without a behavioral effect by pupal day 4 , presumably because the sensory cell had become detached from the hair as it normally does during each molt. Electrical stimulation of the afferent axons at this time, however, did evoke the typical pupal motoneuron response.

\section{Discussion}

The experiments described above provide strong evidence that a change in the central branching pattern of the larval sensory neurons is crucial for their participation in the pupal gin-trap reflex. Treated sensory neurons that failed to alter their larval morphology could not evoke the pupal motor response, even though they were capable of normal stimulus transduction. While new or modified larval interneurons may be required for the pupal reflex, such a change must be accompanied by transformation of the sensory neurons. Since normal sensilla adjacent to treated areas could evoke the gin-trap reflex, it is unlikely that our results can be accounted for by the failure of interneurons to be modified. Thus, like many abdominal motoneurons (Levine and Truman, 1982, 1985), these sensory neurons are retained for a different use at a later stage of life and undergo morphological reorganization during metamorphosis.

The exact relationship between morphological and functional changes is unclear at this point. Within the ganglion in which the sensory neuron processes grow, they must connect with in-

Table 1. Comparison of the total length and number of branch points of sensory neuron terminals under various conditions

\begin{tabular}{llcr} 
Sensory neuron location & $\begin{array}{l}\text { Length } \\
(\mu \mathrm{m}, \text { mean } \pm \text { SD) }\end{array}$ & $\begin{array}{l}\text { No. branch points } \\
(\text { mean } \pm \text { SD) }\end{array}$ & $n$ \\
\hline Gin-trap of untreated pupa & $1476 \pm 66$ & $126 \pm 26$ & 6 \\
Gin-trap on control side of treated animal & $1239 \pm 280$ & $88 \pm 33$ & 26 \\
Presumptive gin-trap region of normal larva & $522 \pm 130^{a}$ & $28 \pm 11^{a}$ & 16 \\
Larval patch on treated pupa & $676 \pm 48^{a}$ & $36 \pm 9^{a}$ & 8 \\
Nonfunctional gin-trap on treated pupa & $752 \pm 170^{a}$ & $42 \pm 17^{a}$ & 13 \\
Treated region after recovery of function & $1316 \pm 427$ & $84 \pm 31$ & 3
\end{tabular}

The terminal arborizations of the sensory neurons were drawn with a camera lucida at $500 \times$ (see Fig. 4) and were then measured with a digitizing tablet and microcomputer.

${ }^{a}$ Indicates that the value is significantly different from neurons on the control side of treated animals, or normal pupae $(p<0.01$; Wilcoxon two-sample test). 


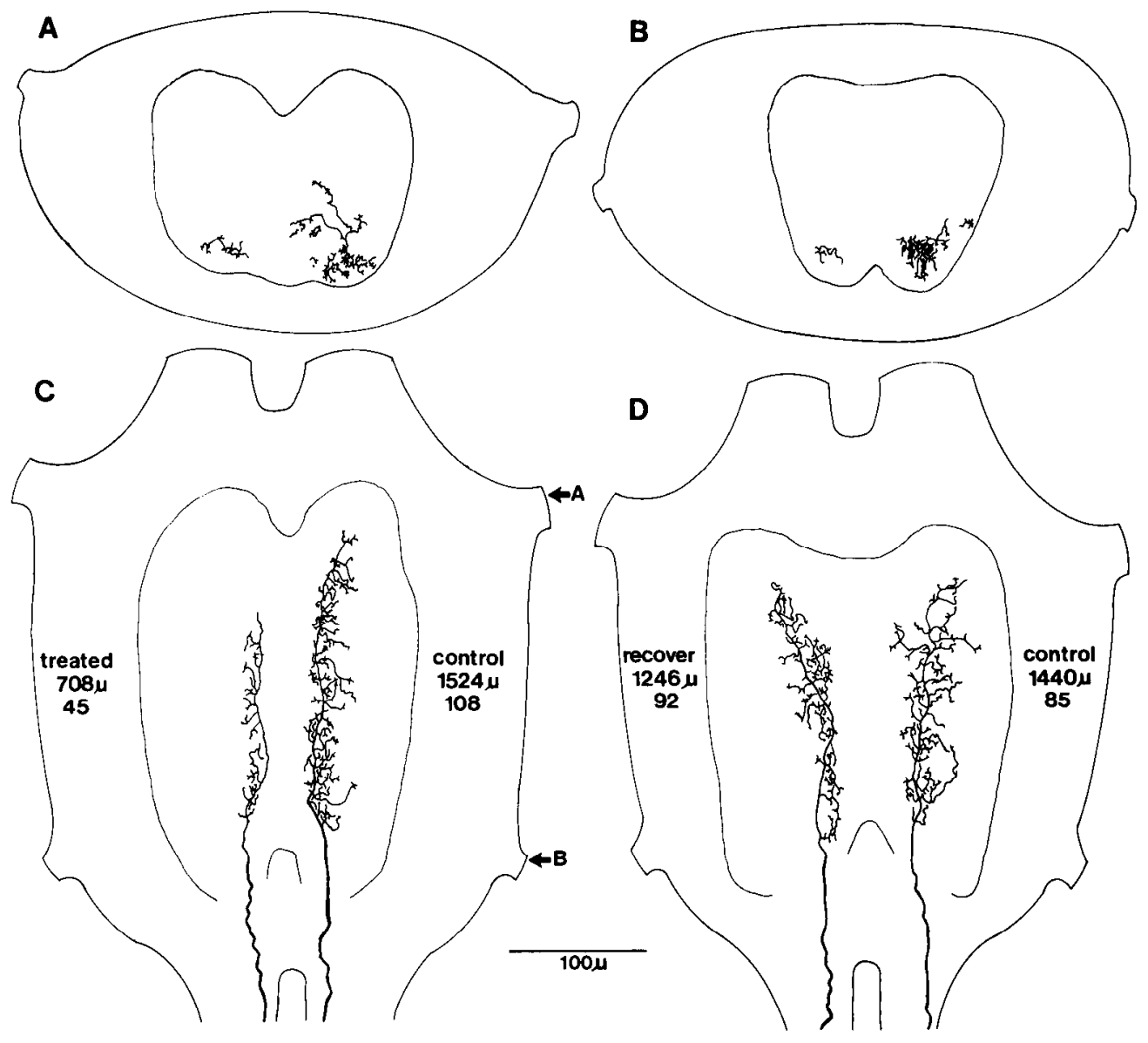

Figure 4. Axonal arborizations of sensory neurons treated with the JH analog. $A-C$, Axonal arborizations of a sensory neuron treated with the $\mathrm{JH}$ analog and unable to evoke the gintrap reflex (left) and a control neuron from the normal contralateral gin-trap of the same animal (right). The cell bodies of these sensory neurons send their axons into the 5th abdominal ganglion, where they branch minimally before proceeding to the 4 th segmental ganglion to terminate (shown). $A$ and $B$, Cross sections of a preparation similar to that shown in $C$ taken at the level of the "dorsal" and "ventral" segmental nerves, respectively (indicated approximately by arrows in $C$ ). $C$, Different preparation viewed in whole mount from the dorsal surface. Numbers refer to the total length of all processes and total number of branch points in the ganglion. $D$, Same as $C$, but the treated sensilla were allowed to recover the ability to evoke the gin-trap reflex during the first $4 \mathrm{~d}$ of the pupal stage before staining.

terneurons that subsequently activate the body-wall motoneurons (Bate, 1973c). The new growth of sensory neuron terminal arbors could allow connections to be made with new target interneurons or simply allow more robust connections with the same targets. Clarification of this point awaits comparison of the pupal targets of the sensory neurons to those known to be postsynaptic to them in the larval stage (R. B. Levine, unpublished observations).

The second significant point to be made from these results is that the morphological and functional changes in the sensory neurons that accompany pupation are induced by the changing hormonal environment. Thus, the endocrine cues that direct the metamorphosis of other tissues are also relevant to the nervous system. In the case of polymorphic epidermal cells, the cuticular proteins synthesized and secreted in response to 20-HE vary, depending on the titer of $\mathrm{JH}$ (Riddiford, 1985). Our results are consistent with the idea that the sensory neurons can similarly exist in at least two distinct states, with a unique morphology and set of synaptic connections appropriate for each stage. Further support for the role of $20-\mathrm{HE}$ in directing metamorphic changes within the nervous system comes from the finding that following pupation, treated sensory neurons recovered their ability to evoke the gin-trap reflex and at the same time acquired the normal pupal morphology within the CNS. This recovery was correlated in time with the increase in the hemolymph ecdysteroid titer that normally triggers the development of adult tissues.

Recent evidence suggests that $20-\mathrm{HE}$ and $\mathrm{JH}$ also regulate the programmed cell death that accompanies both the larval-pupal (Weeks and Truman, 1985), and the pupal-adult (Schwartz and Truman, 1984) transitions, as well as the dendritic reduction that precedes programmed motoneuron death near the end of larval life (Weeks and Truman, 1985). The parallels between steroid control of insect metamorphosis and the regulation of sexual dimorphism within the vertebrate CNS (Arnold and Gorski, 1984) are striking. In both cases, some neurons die (Breedlove and Arnold, 1983), while others alter their geometry (DeVoogd and Nottebohm, 1981) and synaptic interactions (DeVoogd et al., 1985) in response to circulating hormonal cues. It should be possible, therefore, to exploit the relatively simple insect nervous system to analyze the cellular and molecular mechanisms by which steroids regulate developmental changes within the nervous system.

One advantage to working with peripheral sensory neurons is that they do not lie within a dense neuropil. It is, therefore, easier to determine whether endocrine cues act directly on them or upon other cells that then exert a secondary, inductive influence. One possibility, for example, is that our endocrine manipulations disrupted the formation of a peripheral gradient that, it has been suggested, induces the formation of the gintrap from a discrete region of the larval epidermis and directs only those sensory neurons within this region to form central connections appropriate to the new pupal reflex behavior (Bate, 1973c). This interpretation is unlikely, however, because in many cases sensory neurons did not undergo pupal differentiation even though normal external gin-trap structures were formed. It may be, however, that $\mathrm{JH}$ analog treatment rendered the sensory neurons unable to respond to a peripheral gradient. Another possibility is that the increase in sensory neuron arborization is simply a reaction to the partial deafferentation (Murphey and Lemere, 1984) that occurs when some of the sensory neurons in the presumptive gin-trap region die during the prepupal period (Bate, 1972). Our JH analog treatments, by saving such sensilla in larval areas, would remove this sprouting influence. 

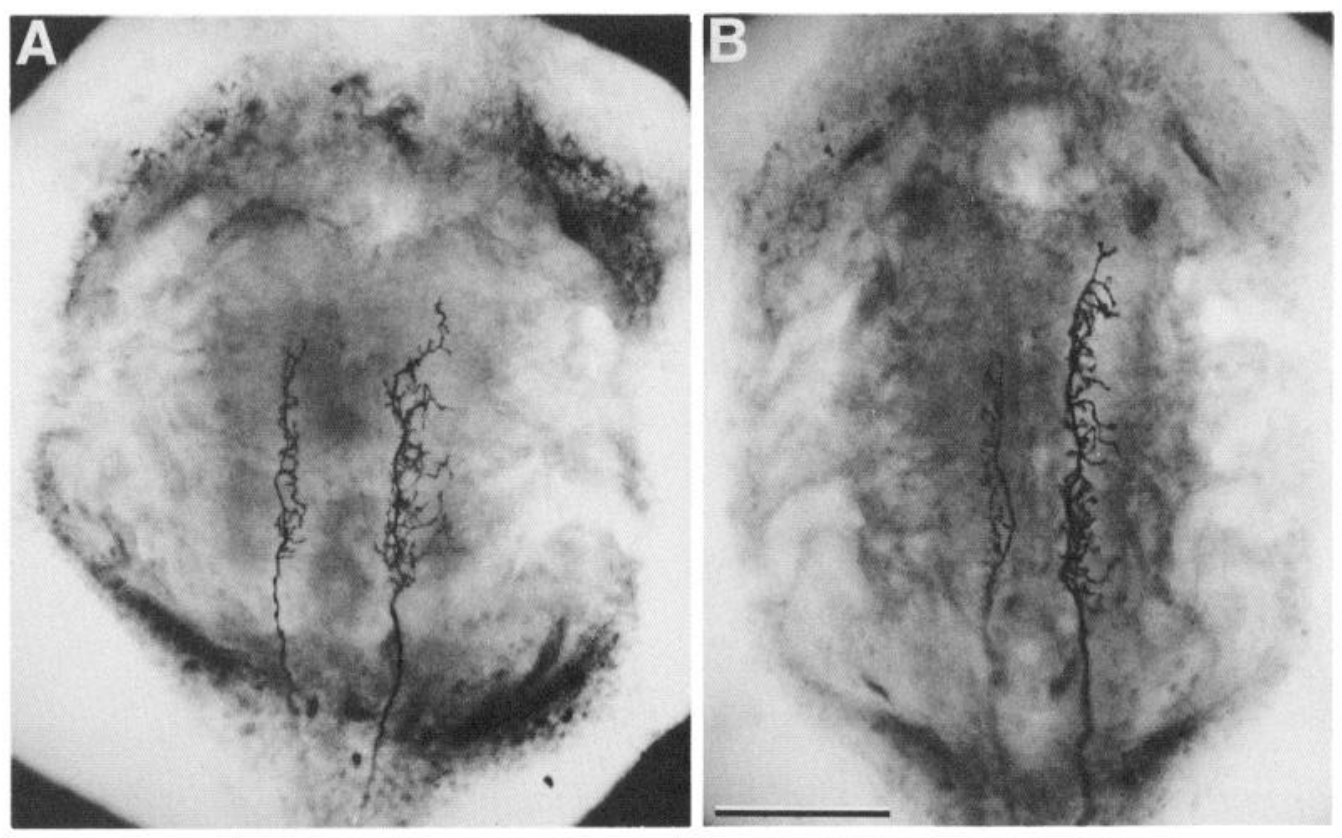

Figure 5. Photographs of cobaltstained sensory neuron terminals within the pupal CNS. In each case the left sensory neuron was treated with the $\mathrm{JH}$ analog and was unable to evoke the gin-trap reflex, while the right neuron was untreated and evoked the reflex. $B$, Same preparation drawn in Fig. $4 C$. Note the greater number and length of processes on the untreated sides. Calibration bar, $100 \mu \mathrm{m}$.

The expanded arbors of neurons originating within normal regions in mosaic gin-traps, however, offer strong evidence against this interpretation of the results.

The dissociation of sensory neuron effects from those on the surrounding tricogen, tormogen, and epidermal cells suggests that their fates are not inexorably linked. Similar conclusions were drawn in analyses of homeotic mutants in Drosophila (Palka, 1982), where apparently wild-type sensory neurons were associated with mutant external structures. During the original development of peripheral sensory structures in insects, a single precursor cell divides twice to generate the sensory neurons along with its associated support cells (Bate, 1978). In one example where the differentiation of these cells has been studied in detail, the sensory neurons begin to elaborate processes well before the support cells generate the hair and socket (Shankland and Bentley, 1983). The differential sensitivity noted in the present study may, therefore, be related to the asynchronous nature of normal development.

The final implication of our results is perhaps the most interesting. The branching patterns of developing neurons are influenced both by the response of their growth cones to local cues (Bentley and Keshishian, 1982; Raper et al., 1983) and by information available at the cell body (Walthall and Murphey, 1984). Since the endocrine manipulation we report produces mosaic insects in which larval sensory neurons enter a pupal $\mathrm{CNS}$, we have been able to examine independently the role that the cell body of a neuron plays in determining the extent of its axon terminal branching. The central ganglia of topically treated insects appear to provide the appropriate local cues for the transformation of sensory neuron terminals during the larvalpupal transition. This conclusion is supported by the fact that the terminals of untreated neurons from the contralateral gintrap or from mosaic traps that are part larval and part pupal showed a normal pattern of sensory arborization. However, when confronted with the same local environment, the treated neurons maintained their larval morphology. These findings show that the local environment within the ganglion is not sufficient to induce terminal growth in these cells. Instructions from the cell body appear to be essential for the axon terminals to respond to these cues.

A conceptually similar experiment was recently reported by Hoskins and Grobstein $(1984,1985)$, who were able to dem- onstrate the influence of the local thyroxine environment on the formation of specific thalamic projections by retinal ganglion cells during amphibian metamorphosis. In this case it appears that thyroxine induces the generation of ganglion cells that are already committed to form specific projections. This contrasts with the present result in which cells already projecting into the CNS were introduced to alter their projection pattern. Nevertheless, both results underscore the importance of intrinsic information in directing neuron growth.

\section{References}

Arnold, A. P., and R. A. Gorski (1984) Gonadal steroid induction of structural sex differences in the CNS. Annu. Rev. Neurosci. 7: 413442.

Bacon, J. P., and J. S. Altman (1977) A silver intensification method for cobalt filled neurons in whole mount preparations. Brain Res. 138: 359-363.

Bate, C. M. (1972) Neuronal control and differentiation of a pupal reflex in sphingid moths. Ph.D. thesis, Cambridge University.

Bate, C. M. (1973a) The mechanism of the pupal gin-trap. I. Segmental gradients and the connections of the triggering sensilla. J. Exp. Biol. 59: $95-107$.

Bate, C. M. (1973b) The mechanism of the pupal gin trap. II. The closure movement. J. Exp. Biol. 59: 109-119.

Bate, C. M. (1973c) The mechanism of the pupal gin trap. III. Interneurones and the origin of the closure mechanism. J. Exp. Biol. 59: 121-135.

Bate, C. M. (1978) Development of sensory systems in arthropods. Handbook of Sensory Physiology, Vol. 9, pp. 2-53, Springer-Verlag, New York.

Bell, R. A., and F. A. Joachim (1978) Techniques for rearing laboratory colonies of tobacco hornworms and pink bollworms. Annu. Entomol. Soc. Am. 69: 365-373.

Bentley, D., and H. Keshishian (1982) Pathfinding by peripheral pioneer neurons in grasshoppers. Science 218: 1082-1088.

Bollenbacher, W. E., S. L. Smith, W. Goodman, and L. I. Gilbert (1981) Ecdysteroid titer during larval-pupal-adult development of the tobacco hornworm, Manduca sexta. Gen. Comp. Endocrinol. 44:302306.

Breedlove, S. M., and A. P. Arnold (1983) Hormonal control of a developing neuromuscular system. I. Complete demasculinization of the male rat spinal nucleus of the bulbocavernosus using the antiandrogen flutamide. J. Neurosci. 3: 417-423.

DeVoogd, T. J., B. Nixdorf, and F. Nottebohm (1985) Synaptogenesis 
and changes in synaptic morphology related to acquisition of a new behavior. Brain Res. 329: 304-308.

DeVoogd, T. J., and F. Nottebohm (1981) Gonadal hormones induce dendritic growth in the adult avian brain. Science 214: 202-204.

Gurney, M. E. (1981) Hormonal control of cell form and number in the zebra finch song system. J. Neurosci. 1: 658-673.

Hoskins, S. G., and P. Grobstein (1984) Induction of the ipsilateral retinothalamic projection in $X$. laevis by thyroxine. Nature 307:730733.

Hoskins, S. G., and P. Grobstein (1985) Development of the ipsilateral retinothalamic projection in the frog Xenopus laevis. III. The role of thyroxine. J. Neurosci. 5: 930-940.

Johnson, S. E., and R. K. Murphey (1985) The afferent projection of mesothoracic bristle hairs in the cricket, Acheta domesticus. J. Comp. Physiol. 156: 369-379.

Kiguchi, K., and L. M. Riddiford (1978) The role of juvenile hormone in pupal development of the tobacco hornworm, Manduca sexta. J. Insect Physiol. 24: 673-680.

Levine, R. B. (1984) Changes in neuronal circuits during insect metamorphosis. J. Exp. Biol. 112: 27-44.

Levine, R. B., and J. W. Truman (1982) Metamorphosis of the insect nervous system: Changes in morphology and synaptic interactions of identified neurons. Nature 299: 250-252.

Levine, R. B., and J. W. Truman (1983) Peptide activation of a simple reflex circuit. Brain Res. 279: 335-338.

Levine, R. B., and J. W. Truman (1985) Fate of abdominal motoneurons during metamorphosis of the moth, Manduca sexta. J. Neurosci. 5: 2424-2431.

Levine, R. B., C. Pak, and D. Linn (1985) The structure, function and metamorphic reorganization of somatotopically projecting sensory neurons in Manduca sexta larvae. J. Comp. Physiol. 157: 1-13.

Mollenhaur, H. H. (1964) Plastic embedding mixtures for use in electron microscopy. Stain Technol. 39: 111-114.

Murphey, R. K., and C. A. Lemere (1984) Competition controls the growth of an identified axonal arborization. Science 224: 1352-1355.
Palka. I. (1982) Genetic manipulation of sensory pathways in Drosophila. In Neuronal Development, N. Spitzer, ed., pp. 121-170, Plenum, New York.

Raisman, G., and P. M. Field (1973) Sexual dimorphism in the neuropil of the preoptic area of the rat and its dependence on neonatal androgen. Brain Res. 54: 1-29.

Raper, J. A., M. Bastiani, and C. Goodman (1983) Pathfinding by neuronal growth cones in grasshopper embryos. I. Divergent choices made by the growth cones of sibling neurons. J. Neurosci. 3: 20-30.

Riddiford, L. M. (1980) Insect endocrinology-action of hormones at the cellular level. Annu. Rev. Physiol. 42: 511-528.

Riddiford, L. M. (1985) Hormone action at the cellular level. In Comprehensive Insect Physiology, Biochemistry and Pharmacology, G. A. Kerkut and L. I. Gilbert, eds., pp. 37-84. Plenum, New York.

Shankland, M., and D. Bentley (1983) Sensory receptor differentiation and axonal pathfinding in the cercus of the grasshopper embryo. Dev. Biol. 97: 468-482.

Truman, J. W., L. M. Riddiford, and L. Safranek (1974) Temporal patterns of response to ecdysone and juvenile hormone in the epidermis of the tobacco hornworm Manduca sexta. Dev. Biol. 39: 247262.

Truman, J. W., and L. M. Schwartz (1984) Steroid regulation of neuronal death in the moth nervous system. J. Neurosci. 4: 274-280.

Walthall, W. W., and R. K. Murphey (1984) Rules for neural development revealed by chimeric sensory systems in crickets. Nature 311 : $57-59$.

Weeks, J. C., and J. W. Truman (1985) Independent steroid control of the fate of motoneurons and their muscles during insect metamorphosis. J. Neurosci. 5: 2290-2300.

Weevers, R. De G. (1966) A lepidopteran saline: Effects of inorganic cation concentrations on sensory, reflex and motor responses in a herbivorous insect. J. Exp. Biol. 44: 163-175.

Wigglesworth, V. B. (1954) The Physiology of Insect Metamorphosis, Cambridge U. P., Cambridge, England. 